\title{
Repair of pectus deformities with sternal support
}

During the past 25 years, 252 children underwent repair of pectus deformities. There were 195 male and 57 female patients, of whom 227 had pectus excavatum and 25 had pectus carinatum. Of the $\mathbf{2 5 2}$ patients, 113 underwent repair at between 2 and 5 years of age. Exercise limitation was reported by $51 \%$, and $32 \%$ had frequent respiratory infections or asthma. Repair was performed through a transverse incision with subperiosteal resection of the lower four or five costal cartilages, from sternum to costochondral junction bilaterally. A transverse wedge osteotomy was made through the anterior table of the sternum, with fracture but no displacement of the posterior table. For children younger than 5 years $(n=108)$, the periosteal sheath of the fifth rib from each side was sewn together behind the sternal tip. For older patients $(n=136)$, a thin steel strut was used for sternal support for 6 months. There were no deaths within the first year. Complications included seroma (16), atelectasis (12), pneumothorax (three), and recurrent chest depression (three). More than $98 \%$ of patients had improvements in exercise tolerance, endurance, respiratory symptoms, and cosmetic appearance; these improvements were considered excellent results. Operation at an early age with routine use of substernal support with minimal preoperative and postoperative testing has provided excellent results at a low cost. (J Thorac Cardovasc Surg 1994;107:37-42)

Eric W. Fonkalsrud, MD, Tansu Salman, MD, Weihong Guo, MD, and Jeffrey P. Gregg, MD, Los Angeles, Calif.

\footnotetext{
$\mathrm{M}$ any changes in the technique for surgical correction of pectus excavatum have evolved during the eight decades since the first repairs were performed by Meyer ${ }^{1}$ and Sauerbruch. ${ }^{2}$ In 1939, Brown ${ }^{3}$ recommended stabilizing the sternum after repair by external traction with a splint (Jacob's ladder), to which a wire from the distal sternum was attached to reduce recurrent depression. Both Lester ${ }^{4}$ and Ravitch ${ }^{5}$ advocated complete excision of all deformed cartilages with perichondrium; however, Ravitch ${ }^{5}$ also divided the intercostal bundles and the xiphoid to isolate the sternum completely. Ravitch ${ }^{6}$ subsequently recommended a posterior rather than anterior transverse sternal osteotomy, into which he placed a small bone graft. The sternum was then stabilized by overlapping the second costal cartilages. Ravitch ${ }^{6}$ further advocated the use of internal fixation for support, particularly

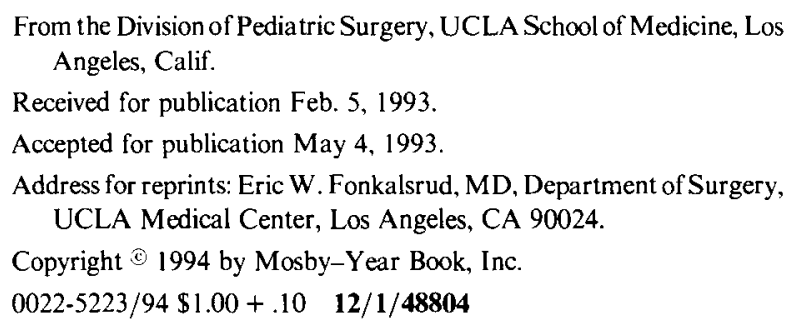

in older patients with a long segment of sternum inferior to the osteotomy. In 1958, Welch ${ }^{7}$ recommended total preservation of the perichondrial sheaths and intercostal muscle bundles, anterior sternal wedge osteotomy, and anterior suture fixation of the sternum at the osteotomy site without internal stabilization, a technique widely used in the United States today.

To avoid recurrent sternal depression after pectus excavatum repair, most surgeons currently favor some method of postoperative sternal fixation. External sternal support has not been used for a few decades; however, a variety of techniques for internal stabilization have been recommended, including a substernal autologous rib strut, Kirschner wires, or Steinmann pins placed behind the lower sternum and attached laterally to the ribs. Thin stainless steel struts have been used with increased frequency during the past several years as temporary supports in adolescents and children with tall body configurations. ${ }^{8}$ For young children, autologous perichondrium placed behind the sternum is a simple technique to provide support without a prosthesis. ${ }^{9}$ Haller and associates ${ }^{10}$ avoided prosthetic or autologous sternal support in favor of a modification of Ravitch's technique of internal suspension, with overlapping of the beveled ends of the lowest normal costal cartilages bilaterally. 


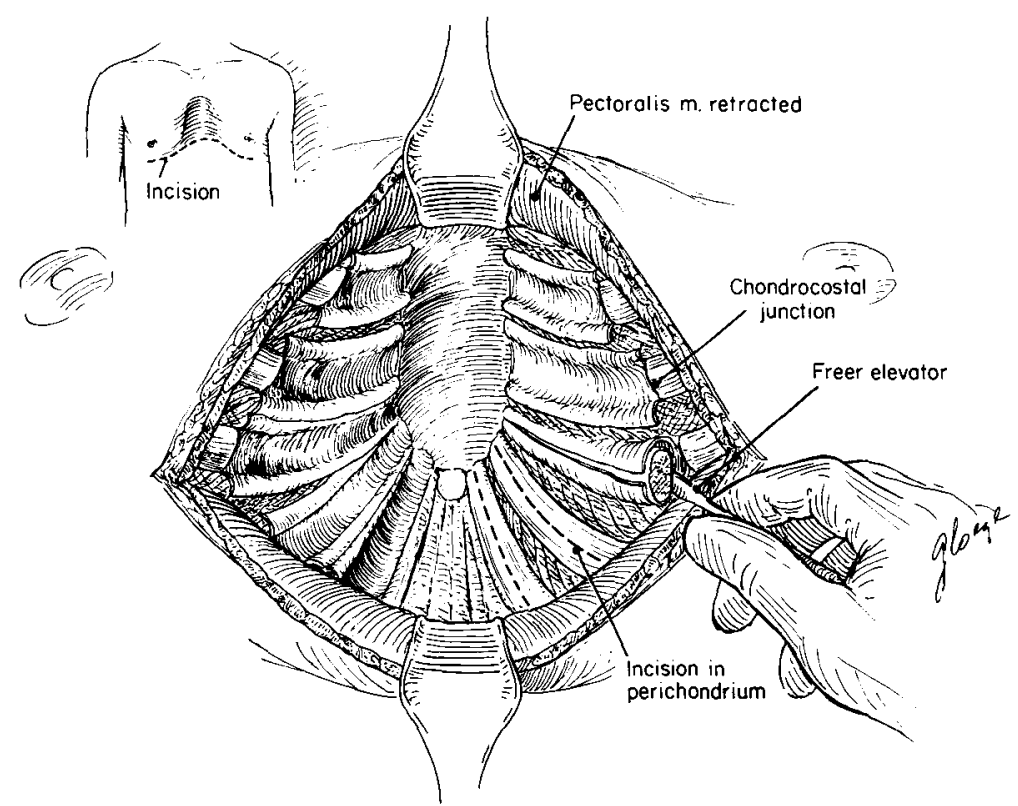

Fig. 1. Through a transverse submammary incision, skin flaps are elevated superiorly and inferiorly and pectoral and rectus muscles are mobilized from lower anterior chest. Lower four to five costal cartilages are resected subperiosteally.

Table I. Age at pectus repair

\begin{tabular}{cc}
\hline Age range $(y r)$ & $\begin{array}{c}\text { No. of } \\
\text { patients }\end{array}$ \\
\hline $2-5$ & 113 \\
$6-10$ & 53 \\
$11-15$ & 51 \\
$16-20$ & $\underline{35}$ \\
TOTAL & 252 \\
\hline
\end{tabular}

This report summarizes a 26-year experience with 252 children who have undergone pectus excavatum or carinatum repair with substernal support from either autologous periosteum or a stainless steel strut.

\section{Patients and methods}

The medical records of all patients who underwent surgical correction of pectus deformities at University of CaliforniaLos Angeles Hospital from January 1968 through December 1992 were reviewed. There were 195 male and 57 female (23\%) patients. Two hundred twenty-seven patients $(90 \%)$ had pectus excavatum deformities; the remaining 25 patients had pectus carinatum anomalies. The deformity was evident within the first few months of life in $84 \%$ of patients; later recognition of the deformity was common among patients with pectus carinatum. A family history of pectus deformity was present in $41 \%$ of patients. The age at the time of operation ranged from 2 to 20 years (Table I). Two hundred nineteen of the operations were performed by one surgeon. The period of follow-up has extended from 7 months to 24 years (median 8.2 years).
Table II. Associated anomalies in patients with pectus deformity

\begin{tabular}{lc}
\hline \multicolumn{1}{c}{ Anomaly } & $\begin{array}{c}\text { No. of } \\
\text { patients }\end{array}$ \\
\hline Functional heart murmur & $78(31 \%)$ \\
Scoliosis & $38(15 \%)$ \\
Congenital heart disease & $9(4 \%)$ \\
Marfan syndrome & 2 \\
Other anomalies & 13 \\
\hline
\end{tabular}

The most frequent complaint, especially for young patients, was related to the unattractive physical appearance of the defect $(n=161,64 \%)$. Mild to moderate exercise limitation and inability to keep up with peers in strenuous athletic activities were reported by 127 patients $(51 \%)$, most frequently those older than 7 years. Eighty-one (32\%) had frequent respiratory infections and $18(7 \%)$ had asthmatic symptoms. Functional heart murmurs were present in 78 patients $(31 \%)$; however, only nine patients had cardiac anomalies (Table II). Two patients had characteristic features of Marfan syndrome. Thirty-five children had mild or moderate scoliosis and three patients had severe spinal deformities (15\%). Three patients had Poland's syndrome. Thirteen patients had other anomalies.

The operative technique used for almost all patients in the study was a slight modification of that described by Ravitch ${ }^{6}$ and Welch ${ }^{7}$ and illustrated in a previous report. ${ }^{9}$ The surgical repair of pectus excavatum includes the following essential features: (1) A transverse skin incision is made midway between the nipples and costal margin, with a slight upward bow in the center (Fig. 1). (2) Skin flaps are elevated over pectoral fascia, with 


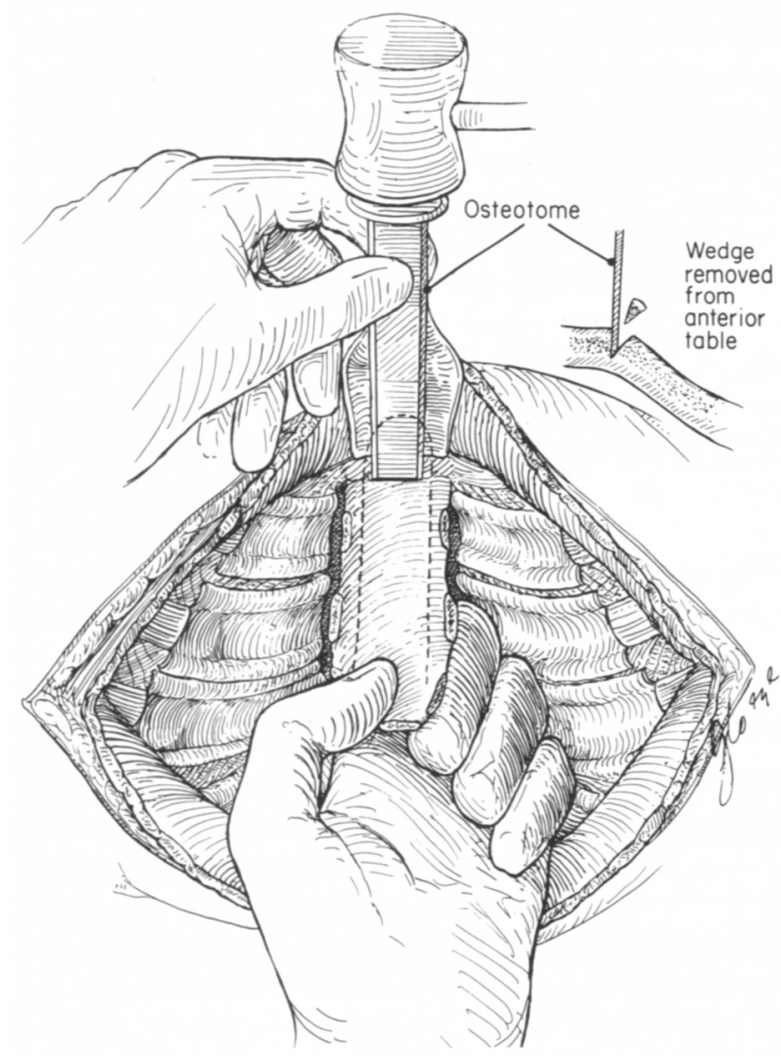

Fig. 2. Xiphoid, intercostal muscles, and perichondrial sheaths are detached from the lower sternum. Transverse wedge osteotomy is made through anterior table of the sternum at the level where posterior depression begins.

electrocoagulation used to minimize blood loss. (3) The pectoral muscles are reflected laterally from attachments to the sternum and costal cartilages with electrocautery. (4) The rectus muscles are detached from the sternum, xiphoid, and costal cartilages. (5) The perichondrium is incised on the midanterior surface of the lower four to five costal cartilages bilaterally, extending from the costochondral junction to the sternum. (6) Abnormal costal cartilages are resected subperichondrially with a Freer elevator (usually fourth through seventh ribs bilaterally), carefully preserving perichondrium. (7) The xiphoid is detached from the sternum and the intercostal muscles and perichondrial sheaths are transected from the sternum, medial to the internal mammary vessels. (8) The substernal space is mobilized. (9) The pleura is incised on the right side of the chest and a small chest tube is inserted. (10) A transverse anterior wedge osteotomy of the sternum is made at the level of the lowest normal rib (Fig. 2). (11) The posterior table of the sternum is fractured without displacement (to maintain adequate blood supply) and then elevated to the desired position. (12) Nonabsorbable sutures are placed through the anterior table of the sternum across the osteotomy. (13) For children younger than 6 years, the perichondrium of the fifth rib on each side is approximated in the midline posterior to the lower end of the sternum with nonabsorbable suture to serve as a support. (14)

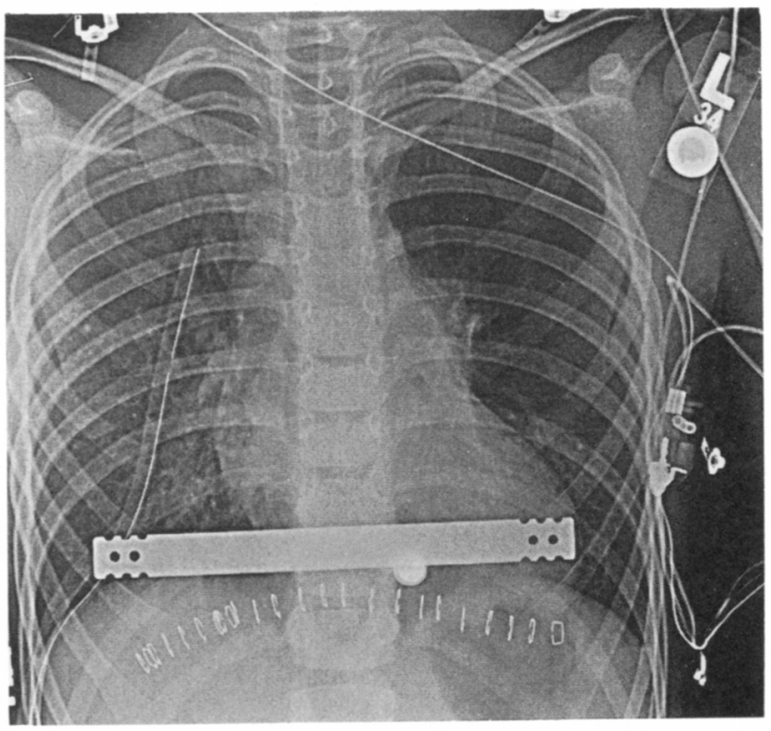

Fig. 3. Immediate postoperative chest roentgenogram shows sternal support bar attached to fifth rib bilaterally. The heart and mediastinum have shifted back to the midline from the preoperative displacement to the left.

Table III. Complications after pectus repair

\begin{tabular}{lc} 
Complication & $\begin{array}{c}\text { No. of } \\
\text { patients }\end{array}$ \\
\hline Keloid scarring & 21 \\
Wound seroma & 16 \\
Atelectasis or pneumonia & 12 \\
Pneumothorax & 3 \\
Recurrent sternal depression & 3 \\
\hline
\end{tabular}

For children older than 6 years, a commercially available stainless steel strut (Baxter Healthcare Corp., Operating Room Division, McGaw Park, Ill.) is placed across the lower anterior part of the chest to support the tip of the sternum; the strut is sutured to the appropriate level rib on each side (fifth or sixth rib) with monofilament suture or wire (Fig. 3). (15) The xiphoid and perichondrial sheaths are sutured to the sternum (Fig. 4). (16) The pectoral and rectus muscles are sutured together over the sternum. (17) Skin is closed with subcuticular absorbable suture and sterile gauze strips or staples. Thorough hemostasis is achieved with electrocautery, and the wound is frequently irrigated with antibiotic solution (Ancef). Intravenous antibiotic (Ancef) is given for 3 days and oral antibiotic (Keflex) is given for 3 additional days. The chest tube is removed within 24 to 36 hours after operation.

During the past 12 years, the duration of the operation has averaged 2.8 hours, and the total period of hospitalization has rarely exceeded 4 days. Blood transfusion was used in fewer than $4 \%$ of patients overall and was used even more rarely during the past 15 years. The stainless steel strut is removed on an outpatient basis approximately 6 months after repair with the patient 


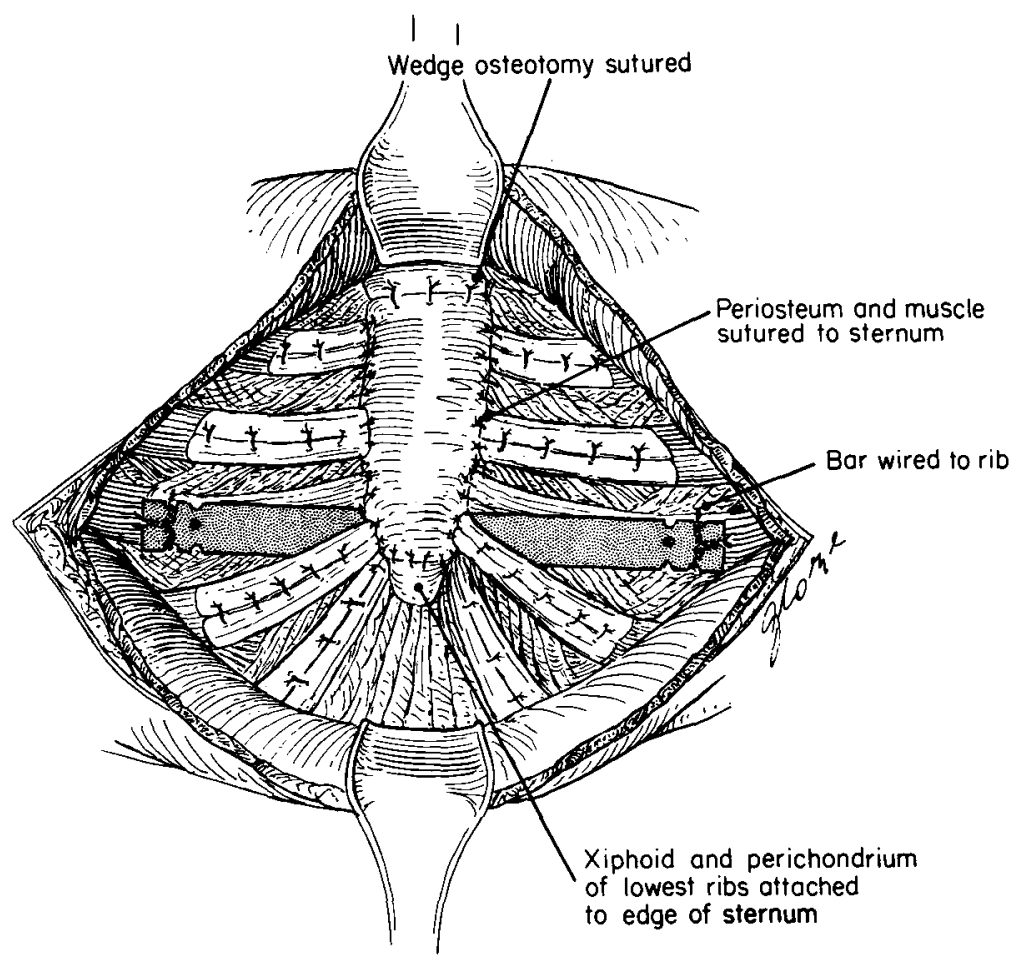

Fig. 4. After gentle fracture of the posterior table of the sternum, osteotomy is closed with nonabsorbable sutures. Xiphoid and perichondrial sheaths are sutured back to sternum. Steel strut is sutured to fifth rib bilaterally, providing support to lower sternum.

under light general anesthesia. Full physical activity was resumed by most patients within 8 weeks.

\section{Results}

More than $90 \%$ of the children with preoperative respiratory symptoms had a decrease in frequency and severity of pulmonary infections after sternal repair. Of the 18 children with asthma, 16 showed clinical improvement after operation, as evidenced by fewer episodes of wheezing and by a $25 \%$ to $40 \%$ decrease in requirement for medications. Almost all children who had indicated some preoperative exercise intolerance (125/127) noted improvement after operation; postoperative increases in stamina and endurance were particularly striking for several competitive runners, swimmers, and basketball players.

Postoperative complications included wound seroma necessitating aspiration in 16 patients, atelectasis or pneumonitis in 10 patients, unintentional pneumothorax in three patients, and mild recurrent sternal depression in three of the early patients (Table III). One patient underwent a secondary repair (16 years ago). Seventeen patients had protrusion of the second or third costal cartilage within 10 years after operation; however, only three patients underwent late resection of additional cartilage. Mild to moderate keloid scarring occurred in 21 patients. There were no deaths within the first 12 months after operation.

\section{Discussion}

Symptoms from pectus excavatum were infrequent during early childhood, apart from an unwillingness to expose the chest while swimming or taking part in other social or athletic activities. Easy fatiguability and decreased stamina and endurance often became apparent during early adolescence, when the child participated in more vigorous physical activities. For all patients undergoing repair, the heart was considerably displaced into the left side of the chest and pulmonary expansion during inspiration was confined. The vast majority of patients had an asthenic habitus, narrow anteroposterior chest diameter, poor posture, and a protuberant abdomen. None of the patients who were evaluated for longer than 3 years showed any evidence of regression of the deformity; on the contrary, almost all patients showed a progressive worsening.

The severity of a pectus excavatum or carinatum 
deformity is usually graded by measuring the distance between the sternum and the spine. Transverse and anteroposterior measurements from a chest computed tomographic scan are accurate; however, they are costly and, in our experience, rarely necessary. ${ }^{15}$ The severity rating score reported by Shamberger and Welch, ${ }^{11}$ which is based on the declination index determined from chest roentgenograms, has been helpful in advising patients and pediatricians regarding the degree of severity of the pectus deformity in occasional patients from our study; however, in no patient did this study indicate that repair should not be performed. We prefer surgical repair between 3 and 6 years of age for all children with moderate to severe deformity because the operation is technically easier at this age, taking approximately 1 hour less operating time than in adolescents. There also appears to be a progressive narrowing of the anteroposterior chest diameter in children who did not undergo operation.

Although there is controversy regarding the severity of cardiovascular and respiratory impairment caused by pectus deformities and the amount of improvement produced by surgical repair, this study and reports from other large clinical series indicate considerable subjective improvement in stamina and endurance, as well as a reduction in pulmonary symptoms with decrease in frequency and severity of respiratory infections, after repair. ${ }^{11-14} \mathrm{~A}$ comprehensive review of the many published reports that indicate improvement in cardiac or respiratory function after pectus defect repair is provided by Shamberger and Welch. ${ }^{12}$ Because of the high expense and often invasive nature of the procedures used for physiologic evaluation before and after pectus defect repair, we have not favored the routine use of such tests for many years.

The basic features of the surgical repair used in our series of patients is similar to that advocated by Shamberger and Welch ${ }^{11}$ and Haller and associates ${ }^{13}$ in two of the largest reported clinical series. In view of the mild recurrent sternal depression that recurred in three of our early patients without sternal support, we have favored the routine use of an internal substernal support, as did Willital $^{14}$ in his experience with 1000 patients. For children younger than 5 years, the distance from the sternal osteotomy to the xiphisternal junction rarely exceeds 4 $\mathrm{cm}$, and the support provided by suturing the perichondrium of the fifth ribs from each side together posterior to the sternum has been sufficient to prevent recurrent depression in any of the 108 patients on whom this procedure was used. This autologous support obviates the need for a second operation to remove the prosthesis. For 136 older patients with a longer segment of sternum inferior to the osteotomy, use of a metal strut has been our

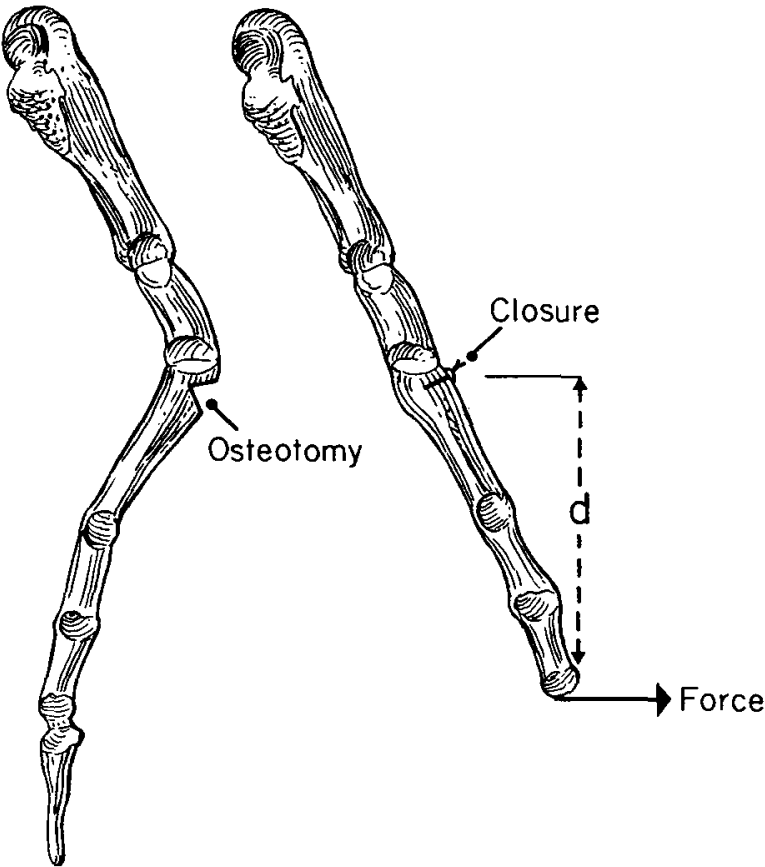

Fig. 5. Lateral view of sternum shows common location of wedge osteotomy with anterior elevation of lower end with repair (xiphoid detached). As distance from the osteotomy to sternal tip increases $(d)$, force necessary to hold the lower sternum in an anterior position increases by the square of that distance.

choice for more than 20 years. According to the physics principle of levers, the force necessary to hold the lower sternum anteriorly increases by the square of the distance from the osteotomy (point of fixed rib support) to the sternal tip (Fig. 5). The distal sternum thus requires four times the support when the segment distal to the osteotomy is $8 \mathrm{~cm}$ in length rather than $4 \mathrm{~cm}$. With strut stabilization, there is negligible paradoxic movement after operation, regardless of the number of cartilage segments resected. The use of struts has allowed more aggressive surgical repair in older patients with severe deformities, repair that occasionally includes resection of deformed bony components in addition to the cartilage. Furthermore, the final contour of the chest wall is consistently better than when no strut is used. When the struts are left for approximately 6 months, removal is a simple procedure performed on an ambulatory basis and recurrent depression is extremely uncommon.

Our early experience with seroma, or subcutaneous fluid accumulation, that frequently necessitated needle aspiration during the first few postoperative weeks after 
the subcutaneous drain was removed has encouraged us to use elective right transpleural drainage for 24 to 36 hours in almost all patients. The requirement for postoperative analgesic medication has been reduced substantially in many teenaged patients by performing an intercostal nerve block on the reconstructed ribs. Only the infrequent patient with associated cardiac anomalies has been placed in an intensive care unit after operation. Meticulous attention to skin closure is necessary to minimize the risk of keloid and hypertropic scarring. The width of the skin flaps appears to correlate with the extent of hypertropic scarring in this group of patients.

This retrospective clinical study confirms the observation that pectus deformities can be repaired with a low rate of complications and short hospital stay. The exceptionally high frequency of improvement in respiratory symptoms, exercise tolerance, and endurance, as well as cosmetic appearance, of more than $98 \%$ of the children in this study support the view that children with severe pectus deformities should undergo repair at an early age. Routine use of substernal support with minimal preoperative and postoperative testing has provided excellent clinical results at a low cost.

\section{REFERENCES}

1. Meyer I. Zur Chirurgischen Behandlung der angebornen Trichterbrust. Verh Berliner Med 1911;42:364-73.

2. Sauerbruch F. Die Chirurgie der Brustorgane. VerlagSpringer, Berlin: 1920:440-4.

3. Brown AL. Pectus excavatum (funnel chest) anatomic basis: surgical treatment of incipient stage in infancy; and correction of deformity in fully developed stage. J THORAC SURG 1939;9:164-84.

4. Lester CW. The surgical treatment of funnel chest. Ann Surg 1946;123:1003-22.

5. Ravitch MM. Operative technique of pectus excavatum. Ann Surg 1949;129:429-44.

6. Ravitch MM. Technical problems in the operative correction of pectus excavatum. Ann Surg 1965;162:29-33.

7. Welch KJ. Satisfactory surgical correction of pectus excavatum deformity in childhood: a limited opportunity. J THORAC SURG 1958;36:697-713.

8. Adkins PC, Blades B. A stainless steel strut for the correction of pectus excavatum. Surg Gynecol Obstet 1961; 113:111-3.

9. Fonkalsrud EW, Follette D, Sarwat AK. Pectus excavatum repair using autologous perichondrium for sternal support. Arch Surg 1978;113:1433-7.

10. Haller JA Jr, Katlic M, Shermeta DW, et al. Operative correction of pectus excavatum: an evolving perspective. Ann Surg 1976;184:554-7.

11. Shamberger RC, Welch KJ. Surgical repair of pectus excavatum. J Pediatr Surg 1988;23:615-22.

12. Shamberger RC, Welch KJ. Cardiopulmonary function in pectus excavatum. Surg Gynecol Obstet 1988;166:383-91.

13. Haller JA Jr, Scherer LR, Turner CS, Colombani PM. Evolving management of pectus excavatum based on a single institutional experience of 664 patients. Ann Surg 1989;209:578-83.

14. Willital GH. Operationsindikation-Operationstechnik bei brustkorbdeformierungen. Z Kinderchir 1981;33:244-52.

15. Haller JA Jr, Kramer SS, Lietman SA. Use of CT scans in selection of patients for pectus excavatum surgery: a preliminary report. J Pediatr Surg 1987;22:904-6. 